MANnheim Research Institute for the ECONomics of Aging

\title{
WHO WEARS THE TROUSERS? \\ A SEMIPARAMETRIC ANALYSIS OF DECISION POWER IN COUPLES
}

Melanie Lührmann and Jürgen Maurer

168-2008

○ $\boldsymbol{m e a - M a n n h e i m ~ R e s e a r c h ~ I n s t i t u t e ~ f o r ~ t h e ~ E c o n o m i c s ~ o f ~ A g i n g ~}$

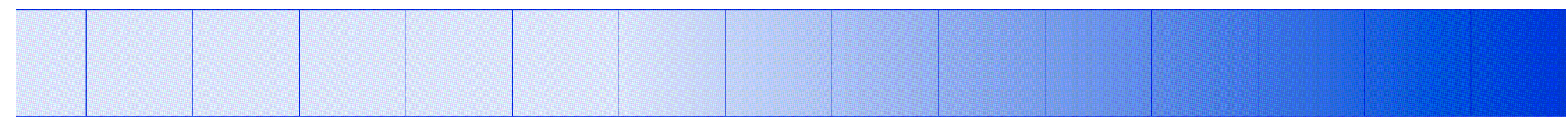

L13, 17_D-68131 Mannheim_Phone +49 621 181-2773/1862_Fax +49 621 181-1863_www.mea.uni-mannheim.de 


\title{
Who wears the trousers? A semiparametric analysis of decision power in couples*
}

\author{
Melanie Lührmann ${ }^{\dagger}$ and Jürgen Maurer ${ }^{\ddagger}$
}

October 8, 2007

\begin{abstract}
Decision processes among couples depend on the balance of power between the partners, determining the welfare of household members as well as household outcomes. However, little is known about the determinants of power. The collective model of household behavior gives an operational definition of decision power. We argue that important aspects of this concept of power are measurable through self-assessments of partners' say. Using such a measure, we model balance of power as an outcome of the interplay between both partners' demographic, socioeconomic, and health characteristics. Advancing flexible, yet parsimonious empirical models is crucial for the analysis, as both absolute status as well as relative position in the couple might potentially affect the balance of power, and gender-asymmetries may be important. Appropriately, we advance semiparametric double index models that feature one separate index for each spouse, which interact nonparametrically in the determination of power.

Based on data from the Mexican Health and Aging Study (MHAS), we find education and employment status to be associated with more individual decision power, especially for women. Moreover, health and income have independent effects on the distribution of power. We also show that contextual factors are important determinants of decision power, with women in urban couples featuring more decision power than their rural counterparts.
\end{abstract}

Keywords: Family Economics, Intra-household bargaining, semiparametric methods, multiple index models

JEL classification: D13, J14, C14

*The authors thank Manuel Arellano, Martin Browning, Andrew Chesher and Karsten Hank for their comments and suggestions. Moreover, we would like to thank Roger Klein and Frank Vella for sharing some of their GAUSS procedures with us. Thanks for funding go to the EU RTN Microdata Methods and Practice.

${ }^{\dagger}$ Centre for Microdata Methods and Practice and Institute for Fiscal Studies. 7, Ridgmount Street, London WC1E 7AE. Email: m.luhrmann@ifs.org.uk

${ }^{\ddagger}$ Mannheim Research Institute for the Economics of Aging. Department of Economics, Universität Mannheim, D-68131 Mannheim. Email: maurer@mea.uni-mannheim.de. 


\section{Introduction}

Since the 1980s, economists have tried to better understand decision processes within the household. The interest mainly arose because of concerns that the individual welfare of some household members, especially children, might be lower than average household welfare. Intrahousehold decision processes are not explicitly captured in the traditional unitary model, in which the aggregate behavior of the household is assumed to mimic that of a single agent. In consequence, new models of household decision-making have been developed. They posit that household members bargain over household outcomes. One of these models is the collective model, which assumes Pareto efficiency of bargaining outcomes. In this model, the household's utility function can be represented as a weighted sum of individual utilities. The weights attached to each partner can thereby be interpreted as their relative decision power.

Identifying which individual characteristics are the driving forces behind decision power is the main objective of this paper. A better understanding of these determinants can help address inequality within households and design targeted policies to promote gender empowerment.

Yet, disentangling individual preferences and power has proven to be difficult, as typically studied family outcomes reflect a blending of both. To unravel decision power from the confounding effects of preferences, we propose the use of a direct survey measure of decision power. Specifically, we exploit self-assessments of say in important family decisions as provided by both partners in the couple. Our measures directly aim at the overall balance of power, thus avoiding the interaction between preferences and decision power that generally confounds studies of particular family outcomes. The feature that our measure is not framed to specific family decisions motivates its interpretation as an ordinal measure for the (unobservable) Pareto weight.

The allocation of decision power in a couple is the result of (strategic) interactions between the partners. The nature of these interactions is thereby influenced by individual, household and societal characteristics, which in turn determine each partner's outside options as well as traditional gender roles on which the partnership is based. For example, factors like age, education, health or income may play a vital role in defining the partners well-being in case of marriage breakdown, and thus affect decision power by shifting their respective participation constraints. Similarly, contextual factors, such as traditional gender roles and social pressure, may also affect the cost of marriage breakdown and thus influence the allocation of decision power within the couple. As a consequence, it appears that individual power is driven by numerous individual and household characteristics as well as societal factors whose interplay between partners determines the final allocation of power within the couple. Reflecting this structure of the allocation process, we assume that we can aggregate each partners enabling factors into one-dimensional indices, whose interaction determines the degree of 
gender equality within the couple.

The relationship between these indices and the final allocation of decision power may thereby be hard to characterize ex ante. On the one hand, we would clearly suspect superior individual characteristics to be associated with better outside options, such that these should manifest themselves in higher reservation utilities (and thus higher bargaining power) as well as more decision power within the family. On the other hand, as decision power is a couple's outcome, it is also clear that we need to consider both partners jointly when studying its allocation. For example, a person with relatively favorable characteristics may nonetheless not have very much say in the couple's decisions if he or she is living with an even more privileged partner. The latter consideration seems especially important, since marriage markets tend to feature positive assortative matching, such that important partner characteristics like education or income tend to be positively correlated within couples. In general, the final allocation of decision power should depend on both absolute and relative levels of empowerment of the two partners, and economic theory gives us little guidance on either their relative importance or how to model their respective effects in a parsimonious, yet flexible econometric framework.

We suggest the use of semiparametric multiple index models as well-suited tools for the analysis of decisions involving multiple decision-makers. As explained in greater detail below, this class of models readily incorporates the potential effects of both absolute and relative levels of partners' characteristics as well as their interactions. We can also obtain simple bargaining power indices in the course of estimating such models. These indices aggregate numerous individual, household and contextual factors into a one-dimensional bargaining power measure for each partner. The respective aggregation weights are obtained endogenously by fitting the models to direct self-assessments of the distribution of decision power within the household.

Based on data from the Mexican Health and Aging Study (MHAS) of 2003, we find education, income and working for pay to be associated with higher levels of decision power for the respective partner, with stronger effects for women than for men. Also, women in cities tend to have somewhat more say in important family decisions than their respective counterparts in rural areas. Moreover, the models feature some interesting gender asymmetries and non-monotonicities, which would have been hard to capture in a fully parametric modelling framework. The remainder of this paper is organized as follows: Section 2 gives some background based on the theoretical and empirical literature on intra-household allocation and household bargaining, further motivates this paper and specifies its contribution. The data is delineated in Section 3, followed by a description of our semiparametric modelling framework in Section 4. The results of our empirical analysis are recorded in Section 5. Section 6 concludes. 


\section{Background}

\subsection{Theoretical models of household behavior}

\section{Unitary versus bargaining models of household behavior}

Until the 1980s, researchers treated households as if they mimicked the behavior of a single agent. In this unitary model of household behavior, income is pooled across household members so that household outcomes, like the demand for goods, depend only on total income and not on its distribution across household members. Yet, important implications of the unitary model, such as income pooling, are usually rejected on micro data, which casts some doubt on its actual validity (see, e.g., Lundberg, Pollak, and Wales (1997) and Thomas (1990)).

Only in the 1980s, economists have become interested in decision processes within households. Manser and Brown (1980) and McElroy and Horney (1981) pioneered modelling household decisions as a bargaining process between partners, which interact strategically in determining household outcomes. These studies have triggered the evolution of new types of household decision models, cooperative (or collective) ${ }^{1}$ and non-cooperative ${ }^{2}$ ones. In noncooperative models, outcomes are generally inefficient, implying that household members who know each other well and make joint decisions every day leave Pareto gains unexploited on a constant basis. This feature is sometimes regarded as implausible in a traditional family setup. ${ }^{3}$ Collective models, on the contrary, assume pareto-efficient household outcomes, but are very general otherwise. Particularly, they do not restrict attention to any specific form of bargaining between the partners. Given Pareto efficiency, the household utility function can be expressed as a weighted sum of the individual utility functions of male and female: ${ }^{4}$

$$
U_{\text {household }}=\mu \cdot U_{\text {male }}+(1-\mu) \cdot U_{\text {female }}
$$

where $\mu$ is the Pareto weight of the male partner.

\section{Decision power and its determinants in the collective model}

The collective framework provides an operational definition of each partner's decision power. Particularly, characterizing household utility as in equation (1), we can interpret the Pareto weight $\mu$ as a measure of power of the male relative to the female partner. On the one hand, it is clear from equation (1) that $\mu$ depends on the particular cardinal representation of $U_{\text {male }}$ and $U_{\text {female }}$, and can therefore not be identified for the usual characterization of preferences based on ordinal utility functions. Despite these cardinality issues, it is clear that -

\footnotetext{
${ }^{1}$ e.g. Apps and Rees (1988), Chiappori (1988), Blundell et al. (2002), Blundell et al. (2005)

${ }^{2}$ e.g. Lundberg and Pollak (1993) and Browning et al. (2006)

${ }^{3}$ It might be more plausible in large, very infrequent decision situations, e.g. moving or fertility choices, or in joint decisions about their children by separated or divorced parents.

${ }^{4}$ For a detailed discussion see Browning, Chiappori, and Weiss (2007).
} 
conditional on any fixed cardinalization of $U_{\text {male }}$ and $U_{\text {female }}$ - higher levels of $\mu$ imply that the male partner's preferences become relatively more important for household utility. As a consequence, the male partner becomes more "decisive" in the determination of optimal household decisions based on maximizing (1), and will therefore enjoy relatively better outcomes ceteris paribus. This point is easily illustrated by considering the extreme cases: If $\mu$ equals one (zero), the household utility function in (1) solely reflects the male (female) partner's preferences, and he (she) acts as a dictator.

While the Pareto weight is fixed in the unitary model, it can be generalized in the collective model to be a function

$$
\mu=\mu(p, y, x, z)
$$

of prices $p$, incomes $y$, individual characteristics $x$ and so-called distribution factors $z$. Characteristics are defined as distribution factors if they neither affect preferences nor budget constraints, but influence household decisions through their impact on the Pareto weight only. From an empirical point of view, their exclusion from both preferences and the budget constraint greatly facilitates an assessment of their respective impact on decision power based on outcome data alone. Examples for such distribution factors include relative ages or education levels, institutional variables affecting the cost of marriage breakdown, social norms or traditional roles. Note also that individual incomes represent a distribution factor, as the budget constraint depends on total income only. Conditional on total income, individual income contributions solely affect the couples' resource allocation through their impact on the Pareto weight.

On the other hand, the effects of prices and total income on decision power are less straightforward to study based on household outcome data alone, as they affect both the budget set and the Pareto weight simultaneously. Similarly, assessing the effects of other individual characteristics, such as age or education, is also complicated by the fact that these may affect outcomes not only through the Pareto weight but also through their effects on preferences. ${ }^{5}$

\subsection{Empirical approaches}

There has been a substantial focus on testing the unitary model in empirical studies on intra-household bargaining. Especially income pooling has been frequently tested (and rejected) (Attanasio and Lechene 2002; Browning, Bourguignon, Chiappori, and Lechene 1994; Browning 1995; Donni 2007; Duflo 2000; Ermisch and Pronzato 2006; Fortin and Lacroix 1997; Hoddinott and Haddad 1995; Lundberg,

\footnotetext{
${ }^{5}$ Chiappori and Ekeland (2006) show that if each partner is the exclusive consumer of at least one commodity, one can uniquely recover individual preferences and the Pareto weight up to the cardinalization. Yet, as a full discussion of various conditions for identification is clearly beyond the scope of this paper, the interested reader may want to consult Browning, Chiappori, and Weiss (2007) and the references therein for further details.
} 
Pollak, and Wales 1997; Phipps and Burton 1998; Schultz 1990; Thomas 1990; Ward-Batts 2003). Given the usual rejections of the unitary model, the empirical literature has investigated the role of the bargaining processes, i.e. effects of changes in bargaining power, on a large number of different household outcomes. Examples include the well-being of children and the resources devoted to them (Kooreman 2000; Lundberg et al. 1997; Phipps and Burton 1998; Thomas 1990), fertility decisions and contraceptive use (Beegle et al. 2001; Duflo 2003; Schuler and Hashemi 1994; Schultz 1990), financial decision-making and savings behavior (Browning 1995; Alessie et al. 2006; Lundberg et al. 2003), charitable giving and informal care-giving (Andreoni et al. 2003; Pezzin and Steinberg Schone 1999). These studies exploit shifts in distribution factors, usually individual incomes, to assess the effects of shifts in bargaining power on household outcomes. ${ }^{6}$

Among these, we would like to highlight Attanasio and Lechene (2002) who also analyze subjective assessments using Mexican data. They exploit the random assignment in the PROGRESA program which gives monetary and in-kind transfers to women. ${ }^{7}$ The study explores the effect of these exogenous income transfers on the self-reported decision weight of women in a number of important expenditure decisions, such as health and education decisions of the children and house expenditures. The authors find that the transfers usually increase women's weight in these decisions. In a second step, they analyze the impact of the transfer on the expenditure patterns of households. The data rejects the unitary model.

Another related study is Beegle, Frankenberg, and Thomas (2001) which takes a more comprehensive approach at modeling bargaining power. They use four potential indicators of power instead of just a shift in individual control over resources to study the effect of household bargaining on the use of prenatal health care. In addition to individual asset ownership, they include factors like education of the partners as well as social status and education of the parents. They find that higher indicators for the female relative to the male partner lead to better prenatal care. The authors conclude that "a woman's bargaining power is not suitably summarized by a single indicator but spans multiple dimensions of a couple's life, including both economic and social aspects of their marriage" (p.143).

Since all of the above studies solely focus on the role of household decision processes in determining outcomes, they do not provide a comprehensive assessment of the distribution of decision power as such nor on its underlying determinants. The only study of the determinants of power is, to our knowledge, Friedberg and Webb (2006). They analyze the allocation of decision power as well as its determinants using a subjective assessment from the 1992 wave of the US Health and

\footnotetext{
${ }^{6}$ As mentioned earlier, the use of distribution factors is ideal for assessing the effects of power on outcomes, as these have - by definition - no effects on preferences or the budget set and therefore allow to disentangle power from potentially confounding effects of changes in preferences or budget sets

${ }^{7}$ These transfers are meant to foster education, nutrition and health.
} 
Retirement Survey (HRS). Specifically, their survey instruments reads: "When it comes to making major family decisions, who has the final say-you or your (husband/wife/ partner)? By "major family decisions" we mean things like when to retire, where to live, or how much money to spend on a major purchase. ". Estimating a parametric bivariate probit model, they find labor market earnings to have a significantly positive but moderate effect on decision power. Other determinants of decision power found in this analysis are education and selfemployment. Cognition, health and parents' education are found to have minor effects on bargaining power.

The above HRS question used in their study may at first appear identical to the MHAS one that we are going to exploit, though a closer look reveals an important difference between the two survey instruments. While the HRS question is framed towards specific areas of decision-making, the one of the MHAS is deliberately general. As a consequence, Friedberg and Webb (2006) most likely consider a composite measure of (general) decision power and item-specific preferences (over retirement, residence or major purchases), while analyzing the MHAS measure should lead to a non-confounded assessment of decision power in general.

\section{Data}

We use data from the 2003 wave of the Mexican Health and Aging Study (MHAS). The MHAS is a nationally representative sample of the noninstitutionalized Mexican population aged $50+$ and their partners. The survey is similar in its design and topics to the US Health and Retirement Study (HRS). It contains extensive information on family and social relations, demographics, and health status as well as childhood conditions, intergenerational transfers, income and wealth, living conditions and anthropometric measures. We restrict the sample to couple households, which leaves us with roughly 3500 couples.

\section{The measure of decision power}

Among the measures of family relations is our survey instrument, a self-assessment of each partner's decision power in the household. The question asked is: "When making important family decisions, who has more weight in the decision-you or your spouse?" As a follow-up, those respondents who stated that they or their partner had more say were asked: "Would you say that you/your spouse have/has much more say in decision-making or somewhat more?" We combine the information from the aforementioned two questions on say in family decisions and define our measure of self-assessed decision power to be a discrete variable taking on five possible values: 1 meaning that the female partner has much more say in the household and 5 being the other extreme that the male partner has much more say. ${ }^{8}$

\footnotetext{
${ }^{8}$ The complete coding of the variable is: $1=$ female partner has much more say, $2=$ female
} 
As mentioned previously, one important feature of this question is that it is not framed or targeted to any specific decision. We therefore expect the answers to be unconfounded by individual preferences, just capturing actual decision power. It is this unique feature of our survey instrument that allows us to interpret our outcome variable as a general measure of overall decision power.

Both partners are asked separately about their assessment of decision power. Interviewers are asked to ensure the privacy of the respondent and they are supposed to stress the confidentiality of the questions and to ask any other person but the respondent to move to another room (INEGI 2003). Table 1 shows the distribution of intra-household decision power according to male and female selfassessments. The most salient observation is the high concentration of households stating that they have equal say which ranges above 57 per cent independent of who answers. As expected, male partners tend to have more say than female partners. In about $30 \%$ respectively $28 \%$ of couples, the male partner has more say, according to the male and female partners' assessments, respectively.

Table 1 here

Our measure is subjective and may thus be an error-ridden proxy for the true allocation of decision power within the couple. Table 2 illustrates agreements and disagreements of partners by taking the absolute value of the difference between assessments. More than 57 per cent of couples agree perfectly in their assessments and 79 per cent agree perfectly or almost perfectly. Strong disagreements, i.e. situations in which both partners think they (or their partner) have (much) more decision power, are seldom, and occur only in 3.5\% of the cases. A closer look at the disagreements reveals that in these cases, the respondents generally report to have more decision power than granted to them by their respective partner. Hence, a relative overstatement of one's own power, seems to be the main cause for disagreement. Nonetheless, we view the general consistency of answers across partners as comforting evidence regarding the reliability of our survey instrument.

Table 2 here

One way to interpret the existing differences in partners' assessments would be to attribute them to classical measurement error. ${ }^{9}$ Alternatively, such reporting differences may be due to gender-specific reporting styles and thus feature systematic over- or underreporting by gender. In our analysis, we take these interpretations into account.

partner has somewhat more say, $3=$ equal say, $4=$ male partner has somewhat more say, $5=$ male partner has much more say.

${ }^{9}$ This approach is for example taken by Friedberg and Webb (2006). 


\section{Explanatory Variables}

We relate the above self-assessments of decision power to several demographic, socioeconomic and health characteristics of the two partners to assess their respective impact on the allocation of power within the couple. Specifically, the characteristics included in each partner's bargaining power index are: age and age squared, household wealth and household wealth squared, individual income and income squared, years of education, work status, and health variables, i.e. dummy variables capturing the existence of mobility limitations, any problems with activities of daily living (ADLs) or instrumental activities of daily living (IADLs). ADLs are activities related to personal care and include bathing, showering, dressing, getting in or out of bed or a chair, using the toilet and eating, while IADLs relate to independent living and include preparing meals, shopping for groceries or personal items, performing housework, and using a telephone. Finally, the indices include two dummies classifying the level of urbanity of the area in which the household is situated. Table 3 presents basic summary statistics for all variables used in the analysis.

Table 3 here

\section{Econometric Models}

\subsection{Generic framework}

Economic theory and empirical studies to date do not give much guidance on what the determinants of decision power are nor how they affect the balance of power. In our analysis of the determinants of decision power, we thus include a rich set of potentially important individual and household characteristics. Particularly, we assume that each partner is endowed with some latent level of bargaining power, which can be modeled as a linear combination of this large set of demographic, socioeconomic and health characteristics. Decision power is then determined by the potentially complex interplay of the two bargaining power indices.

Our modelling approach has the particular advantage that it allows us to reduce the dimensionality of the empirical model by aggregating the determinants of individual decision power into just two distinct indices, one for each partner. Given this double index structure, we can model any interactions between the two indices fully nonparametrically without facing the well-known curse of dimensionality. As such, our model can easily accommodate complex interactions of the partners' characteristics as well as contextual distribution factors that may influence the allocation of decision power within the couple.

We consider several econometric models of the general form

$$
f\left(Y_{i} \mid X_{i}^{M} \beta^{M}, X_{i}^{F} \beta^{F}\right)=g\left(X_{i}^{M} \beta^{M}, X_{i}^{F} \beta^{F}\right)
$$


where $f\left(Y_{i} \mid X_{i}^{M} \beta^{M}, X_{i}^{F} \beta^{F}\right)$ denotes a parameter of interest, such as a conditional probability or conditional expectation function, related to the self-reported measure of bargaining power $Y_{i}$, while $X_{i}^{M} \beta^{M}$ and $X_{i}^{F} \beta^{F}$ denote the indices of the male and female partner in couple $i . g(\cdot, \cdot)$ in turn denotes a bivariate nonparametric mapping of the two indices into self-reported decision power. Being nonparametric, the mapping $g(\cdot, \cdot)$ allows for potential non-linearities, nonmonotonicities as well as fully flexible interactions between the two indices in determining $Y_{i}$. From an ex ante perspective, all of these features may be potentially important. While higher levels of bargaining power seem instrumental for generating more say in the household, the realized allocation of power will most likely depend on the bargaining power of the partner as well. At the same time, just looking at relative bargaining power may be oversimplifying. Thanks to larger opportunity sets, female partners with higher levels of bargaining power may, for example, be able to enforce equal say largely irrespective of their partners' characteristics, whereas less advantaged women may be vulnerable to less favorable allocations of power due to their lack of outside options. Additionally, attitudes may also differ across socioeconomic strata and gender, with some strata regarding gender equality as a value per se that does not require any back-up in terms of high and/or equal bargaining power of the respective partner. In an exploratory investigation like the one considered here, it seems thus prudent to advance a "local" nonparametric estimation strategy that can incorporate all of the above considerations.

\subsection{Conditional expectations}

Using the generic modelling framework outlined above, we estimate four different empirical specifications, some of which require a further specialization of (3). For primary analysis, we treat the partners' self-assessments as cardinal measures of decision power (possibly subject to classical measurement error, e.g. in the case of disagreements) and take the average of both partners' assessments as our dependent variable $Y_{i}$. Treating $Y_{i}$ as a cardinal continuous measure ${ }^{10}$, we can estimate a standard semiparametric double index model for the conditional expectations of $Y_{i}$ given the indices $X_{i}^{M} \beta^{M}$ and $X_{i}^{F} \beta^{F}$, i.e. $E\left[Y_{i} \mid X_{i}^{M} \beta^{M}, X_{i}^{F} \beta^{F}\right]$. Estimates for the index coefficients $\widehat{\beta^{M}}$ and $\widehat{\beta^{F}}$ are thereby obtained by applying the semiparametric least squares procedure of Ichimura and Lee (1991), i.e. as

$$
\left(\widehat{\beta^{M}}, \widehat{\beta^{F}}\right)=\underset{\left(\beta^{M}, \beta^{F}\right)}{\arg \min }\left(Y_{i}-\widehat{E}\left[Y_{i} \mid X_{i}^{M} \beta^{M}, X_{i}^{F} \beta^{F}\right]\right)^{2}
$$

where $\widehat{E}\left[Y_{i} \mid X_{i}^{M} \beta^{M}, X_{i}^{F} \beta^{F}\right]$ denotes the predicted value from a bivariate nonparametric regression of $Y_{i}$ on two candidate indices $X_{i}^{M} \beta^{M}$ and $X_{i}^{F} \beta^{F}$ respectively.

\footnotetext{
${ }^{10}$ All of these assumptions are obviously fairly restrictive and will be further elaborated on in due course.
} 
Thus, $\widehat{E}[\cdot \mid \cdot, \cdot]$ takes the place of the nonparametric link function. Although the assumptions of cardinality, continuity and classical measurement error are far from innocuous, we consider our initial model as useful benchmark for a first exploratory investigation of the main relationships between decision power and the sociodemographic characteristics of the partners.

\subsection{Ordered response models}

To check the robustness of our initial findings with respect to a more stringent sample selection as well as an more accurate ordinal interpretation of the decision power self-reports, we perform further regression analysis using more refined empirical models. Firstly, we restrict our estimation sample to those couples where both partners agree on the distribution of say within the household. The main aim of this sample selection is to alleviate the potential impact of measurement error that plagues conflicting assessments across partners. A second strategy for dealing with conflicting assessments is to allow for gender-specific reporting styles and analyze the assessments of male and female partners separately. Both strategies have the additional advantage that we can interpret our generated decision power variable as an ordinal outcome measured on its original five point scale and estimate conditional probabilities for each of its potential realizations. ${ }^{11}$

To account for the ordinal nature of $Y_{i}$, we estimate a semiparametric double index ordered response model adapting the estimators of Klein and Spady (1993), Klein and Sherman (2002) and Klein and Vella (2006) respectively. Considering two consecutive outcomes $j-1$ and $j$ with $j \in\{1,2,3,4,5\}$ of the self-reported decision power variable $Y_{i}$, we can rewrite the conditional probabilities for each possible outcome as

$$
\begin{aligned}
& P\left(Y_{i}=j \mid X_{i}^{M} \beta^{M}, X_{i}^{F} \beta^{F}\right) \\
= & P\left(j-1<Y_{i} \leq j \mid X_{i}^{M} \beta^{M}, X_{i}^{F} \beta^{F}\right) \\
= & P\left(Y_{i}>j-1 \mid X_{i}^{M} \beta^{M}, X_{i}^{F} \beta^{F}\right)-P\left(Y_{i}>j \mid X_{i}^{M} \beta^{M}, X_{i}^{F} \beta^{F}\right)
\end{aligned}
$$

The conditional probabilities $P\left(Y_{i}=j \mid X_{i}^{M} \beta^{M}, X_{i}^{F} \beta^{F}\right)$ can thus be conveniently analyzed by estimating conditional probabilities of binary events of the form $\left\{Y_{i}>j\right\}$, which can then be stacked to obtain a quasi-likelihood function for the underlying ordered response model. We estimate the index coefficients $\widehat{\beta^{M}}$ and $\widehat{\beta^{F}}$ by maximizing the thus constructed quasi-likelihood function over $\beta^{M}$ and $\beta^{F}$, i.e. as

$$
\left(\widehat{\beta^{M}}, \widehat{\beta^{F}}\right)=\underset{\left(\beta^{M}, \beta^{F}\right)}{\arg \max } L\left(\beta^{M}, \beta^{F}\right)
$$

\footnotetext{
${ }^{11}$ Our initial analysis requires averaging of the two assessments across partners and thus implies a cardinal interpretation of $Y_{i}$, which is then also reflected in our modelling strategy that focusses on $E\left[Y_{i} \mid X_{i}^{M} \beta^{M}, X_{i}^{F} \beta^{F}\right]$ as our main object of interest.
} 
with

$$
L\left(\beta^{M}, \beta^{F}\right)=\sum_{i=1}^{N} \sum_{j=1}^{5} I\left\{Y_{i}=j\right\} \cdot \widehat{P}\left(Y_{i}=j \mid X_{i}^{M} \beta^{M}, X_{i}^{F} \beta^{F}\right)
$$

In this setup, the conditional probability functions $\widehat{P}(\cdot \mid \cdot, \cdot)$ are estimated nonparametrically and thus take the place of the nonparametric link function $g(\cdot, \cdot)$ of the generic framework.

\section{Results}

Using the above modelling strategies, we obtain three sets of results pertaining to the analysis of averaged assessments, agreements, and gender- specific reports respectively. For each set of results, we present our findings in three steps. Firstly, we discuss how the partners' sociodemographic characteristics aggregate into our bargaining power indices. These estimation results reveal the trade-off between different characteristics of the partners with respect to the allocation of decision power in the couple and allow us to assess which of these enter the bargaining power indices statistically significantly. Yet, the indices can of course only be interpreted in connection with the nonparametric link function, which maps them into the individual assessments of decision power. Hence, we plot this link function, thus showing the link between the different combinations of the genderspecific indices and the intra-household allocations of power. Finally, we present estimations for the overall effect of a change in each individual or household characteristic on the allocation of decision power, as mediated through both the index aggregation as well as the nonparametric link function. Specifically, we compute average partial effects (APE), where we keep all characteristics but one at their actual values and vary only the respective variable of interest. The exact variable changes that we use to compute the APE are shown in Table 4.

Table 4 about here

\subsection{Conditional expectations: Average assessments}

The first specification treats the assessments of both partners as cardinal variables, potentially subject to (classical) measurement error. Under these assumption, we can average the partners' reports and use the resulting couple-specific mean assessment as outcome of interest.

While the effect of each of the partners' characteristics on the balance of power will be discussed later using the APE (see Table 6), we first present the parameter estimates for the two bargaining power indices in Table 5. The estimations 
show that individual income, education and working for pay increase the values of both partners' indices, while poor health tends to lead to lower index levels (with the only exception of the fairly prevalent mobility limitations of women). The effects of age on the indices are non-monotonic, though increasing over most of the relevant age range. Finally, living in more rural areas increases the index for male partners. Female partners feature lower index values in rural areas and medium size cities compared to big cities, but the estimated effects are not monotonic. In this regard, it is, however, important to note that city size is a couple-level variable whose effects can thus only be assessed by varying its values for both partners simultaneously, which makes its interpretation somewhat less straightforward.

Regrettably, the precision of the resulting estimates is somewhat disappointing. Particularly, the index coefficients for the male partners are estimated very imprecisely and appear statistically insignificant throughout, with the exception of the nonlinear effects of age. For the female partners' characteristics, however, we obtain significant estimates for the effects of education, labor market status and degree of urbanity, beyond the nonlinearities in age already documented for men. Overall, the relative signs and sizes of the estimates are by and large in line with prior expectations, even if estimated relatively imprecisely, at least for the male partners.

\section{Table 5 about here}

In the next step, we investigate how the estimated indices map into actual allocations of decision power and whether the resulting estimate of the nonparametric link function does in fact provide support for our interpretation of the estimated indices as measures of bargain power. Panel a of Figure 1 shows the joint density of the two indices to establish the relevant support of the data. The red curves depict the combinations of male and female index values that appear most frequently in the data, blue and black lines depict still high, but decreasing frequency. Frequent combinations of male and female partners' index values lie roughly in the interval $[0.2,0.85]$ for the male and $[0.18,0.5]$ for the female index. As nonparametric methods do not allow for off-support predictions, we show the nonparametric link function only for areas within these intervals (depicted by the black square). ${ }^{12}$

Panel $b$ of Figure 1 presents our estimate for the link function. The red area in Figure 1b depicts index combinations that render the highest value of male decision power. Blue lines represent lower values of the estimated conditional expectations function while black represents the lowest estimates, i.e. the outcomes that are most favorable for female partners.

\footnotetext{
${ }^{12}$ The same procedure will be applied in the other two specifications.
} 
Figure 1 about here

As expected, decision power is generally somewhat skewed towards more say of male partners, since the estimated values for the conditional expectations function are larger than three for most of the support.

Beyond the general tendency towards more say of men, expected decision power displays considerable gradients with respect to the estimated indices which support our interpretation as bargaining power indices. Particularly, for given index values of the male partner, decision power of the female partner is increasing in her own index values. A similar pattern emerges for male partners. For given index values of the female partner, expected decision power of men is usually increasing in their own index values, again supporting an interpretation of the estimated indices as measures of bargaining power. Furthermore, the effects of increasing index values for male and female partners seem to be largely off-setting. Specifically, decision power seems to be largely unaffected, when we consider changes in both indices along their joint distribution. While these general patterns are largely in line with the (common) idea that it is the relative standing of the two partners that is driving the final allocation of say, we also find some interesting evidence for important asymmetries and non-monotonicities, which would have been hard to unravel in a standard parametric framework. Particularly, we find that for lower index values of the female partner, decision power of the male partner is first increasing, but then decreasing in the man's index. It thus appears that the gender asymmetries in decision power are at their highest in couples where the woman features a low and the man a medium index level. Even higher index values of the male partner do then lead to somewhat more equality in say, suggesting changing gender attitudes towards the upper tail of its distribution. Hence, while we find that the relative standing of the partners plays the major role in determining the allocation of power within the couple, we also discover some more complex gradients of decision power across the index distribution, which seem difficult to capture in more restricted frameworks focussing on relative effects only.

\section{Table 6 about here}

Given our estimates of the index coefficients and the link function, we can assess how changes in the underlying characteristics of the partners lead to different allocations of say. Specifically, we can compute average partial effects (APE) that summarize the total effect of a variable change as mediated by both the index shift and its associated mapping into expected decision power.

The first column in Table 6 presents probability changes if only the male partner's characteristics are changed. Column two reports the impact of changes of the female partner's characteristics accordingly, while simultaneous changes in the characteristics of both partners are considered in the last column of Table 6 . 
Reflecting the estimated index coefficients and the nature of the nonparametric link function, the APE for each individual set of variables can be summarized as follows:

1. Higher age is associated with higher decision power of the respective partner.

2. Higher individual income leads to higher decision power of the respective partner earning it. This corresponds to the notion in the empirical literature that control over financial resources is a major determinant of bargaining power.

3. Higher educational attainment increases the respective partners' decision power.

4. Labor force participation enhances one's power.

5. The positive effects of education and working for pay on women's outcomes persist if we consider comparable changes for both partners simultaneously. Thus, a couple with two highly educated working partners tends to feature relatively more decision power for the female partner than a couple with two low educated partners neither of whom is working.

6. Being in bad health decreases decision power.

7. Richer households feature relatively more decision power of the male partner.

8. Rural areas feature more traditional gender role outcomes with higher decision power of men.

Yet, it bears repeating that some of the above characteristics do not enter the respective indices statistically significantly, especially for the male partner. In sum, it appears that based on our initial model, educational attainment and labor market status stand out as the key individual-level determinants of bargaining power, with some additional contextual influences related to the size of the couple's city of residence. Apart from being comparatively large, these effects are also statistically significant, at least for the female partner.

\subsection{Ordered responses: Agreements and gender-specific re- ports}

While the results of our initial analysis based on a cardinal interpretation of the self-reports are easily interpretable and thus useful as a benchmark, the econometric model may be seen as overly restrictive. Firstly, the construction of the 
outcome variable as an average of the two assessments does not reflect the ordinal nature of our survey instruments. While representing a convenient way to combine both partners' assessment on the same outcome, the averaging is based on a somewhat arbitrary metric. This hinders a straightforward interpretation of our estimation results in terms of the original (ordinal) statements stemming from the survey question. Secondly, even conditional on a cardinal interpretation of the survey measure, our initial results hinge upon the additional assumption that measurement and reporting errors are random. There might be good reasons why this assumption is not warranted. Particularly, disagreements between partners could also be explained by gender-specific reporting styles, which often plague self-reported survey data (Lee and Waite 2005).

We therefore advance two alternative empirical models to address the robustness of our findings to both an ordinal interpretation of the survey instrument as well as potential gender-specific reporting styles. Firstly, we restrict our analysis to couples with non-conflicting assessments of decision power, deleting all disagreements from our estimation sample. This strategy takes each partners assessment at face value and does not require any aggregation of the partners assessments. Hence, we do not require a cardinal interpretation of our survey measure, but can instead estimate a semiparametric double index model for ordered responses that fully reflects the ordinal nature of our survey instrument. Our second robustness check fully accounts for the potential existence of gender-specific reporting styles by analyzing male and female assessments separately. Again, separate analysis by gender does not require any aggregation of outcomes and thus allows us to use the more appropriate ordered response model. Beyond checking the robustness of our initial findings, we would also expect to obtain improved precision in the resulting estimates based on a more rigorous interpretation of our survey instrument.

\section{Agreements}

Restricting the sample to couples with non-conflicting assessments of say leads to very similar results as our initial analysis based on average assessments. Table 7 presents the corresponding estimates for the index coefficients while Figures 2a through $\mathrm{f}$ plot the nonparametric link functions for the conditional probabilities of every outcome. The relative sizes of the index coefficients seem largely in line with our previous estimates. Also, the shape of the probability plots is largely comparable with the evidence presented before, particularly as the graphs feature the same non-monotonicity in the male partner's index that we had documented earlier.

Table 7 about here

Figure 2 about here

Table 8 about here 
To summarize the entire relationship between the partners' characteristics and each possible outcome, we can again compute average partial effects for each set of variables, as presented in Table 8 . The estimations indicate strong effects of employment status and education, especially for female partners. In this context, it is also worth noting that both employment status and education enter the two bargaining power indices statistically significantly. Whilst male labor force participation boosts his decision power, female labor force participation increases the probability of equal say by about as much as it decreases the probability that he has much more say. We find a similar effect for educational attainment: While a higher education level generally increases the decision power of the respective partner, the effect is much stronger for women. The estimated gender-asymmetry of the effects of both work status and education have therefore important implications for gender empowerment. Particularly, comparable simultaneous changes of both partners characteristics generally leads to an improvement of the situation of the female partner, characterized by a shift towards a more equal distribution of decision power within the couple.

Beyond employment status and education, health appears to also play an important role in determining decision power. Worse health is generally associated with less decision power of the ill person, though the associated index coefficients are only statistically significant for the male partners. Finally, living in more rural areas also increases the say of the male partner substantially, and some of the associated index coefficients enter the model statistically significantly.

In sum, we find that our analysis based on agreements largely confirms the findings of our initial estimates. Employment status, education and health status are the most important individual-level determinants of decision power in the couple. Moreover, we also find some indication for important contextual effects as proxied by the size of the couple's city of residence.

In the next subsections, we take into account that men and women may have different reporting styles and analyze male and female reports separately.

\section{Gender-specific analysis: Male partners' assessments}

Table 9 presents the estimated index coefficients analyzing male assessments only. Again, the relative contributions of our control variables are pretty much in line with earlier results. Yet, our gender-specific analysis results in a remarkable increase in statistical precision, such that almost all of our control variables enter the model statistically significantly, some even at the $1 \%$ level.

The nonparametric link functions in Figures $3 \mathrm{~b}$ through $3 \mathrm{f}$ again illustrate the probabilities for each of the five outcome possibilities conditional on the index values of the two partners. The link functions are also in line with the previous findings. Apart from highlighting the generally positive dependence between the partners' index values and decision power, they again feature the previously documented non-monotonicity of say in the male partner's index, conditional on low 
index values for the female partner.

Table 9 here

Figure 3 here

Table 10 here

Now, we turn to the discussion of the characteristics contained in the respective indices, and their quantitative impact on the balance of power within the household. Table 10 indicates that a partner's decision power increases with his or her age, income, education, labor force participation and health status. Among these individual characteristics, education, employment status and health have once again the largest effects. Also, the estimated effects of education remain asymmetric across gender, indicating that simultaneous improvements in educational attainment for both, male and female partners, are generally associated with a more equal distribution of say in the couple. On the other hand, we do not find such asymmetries for employment status. While we estimate large beneficial effects of active labor market participation for both partners, these tend to be largely offsetting when changing their labor market status simultaneously. The effects of health, however, are again fairly asymmetric, indicating that adverse health events tend to lead to a more severe loss of power for male than female partners. Finally, while household wealth does not display any clear-cut effect on the distribution of power, we once more find a strong tendency for more say of the male partner in more rural areas.

Gender-specific analysis: Female partners' assessments

Our last robustness check focusses on the self-assessments of female partners, thus judging the effects of our control variables subject to female reporting styles. Table 11 presents the associated parameter estimates for the two gender-specific indices, while Figures 4a to f present the estimated link functions mapping the two indices into actual outcome probabilities.

Table 11 here

Figure 4 here

While we find statistically significant effects for most female characteristics, none of the coefficient estimates of the man's index enter the model statistically significantly. It thus seems that women's perception of their decision power relates more to their own characteristics. Regarding the point estimates, however, the results are similar to the previous ones. As highlighted by our partial effect estimates, education, employment and health status, as well as the living area are the main driving forces underlying the allocation of decision power in the couple. Moreover, their respective effects are generally stronger for female partners, such that simultaneous improvements in individual characteristics still tend to lead to 
more favorable outcomes for women, shifting the distribution of power towards equal say.

Table 12 here

\subsection{Main findings}

We find the same key determinants of decision power in all three specifications. Also, the estimates are more pronounced and more precisely estimated for female partners, indicating that their characteristics feature a more clear-cut relationship with self-assessed decision power.

The main driving forces of decision power are education and work status and to a lesser extent health status and individual income. Moreover, we often find that individual characteristics affect decision power of the partners asymmetrically in terms of their magnitude, with stronger positive effects for female partners. As a consequence, improving the characteristics of both partners is not perfectly offsetting, but leads to a more equal distribution of say within the couple. Finally, we generally find that more urban couples have a more equal distribution of say, indicating an important role for contextual effects such as more traditional gender roles in rural areas.

The nonparametric link functions from all of the above estimations feature fairly similar patterns. Increasing index values are generally associated with higher levels of say for the respective partner, apart from the documented non-monotonicity in the male partners' index conditional on low index values for the female partner. As a final robustness check, we recompute the indices of all four models for the entire sample and assess the correlation of the indices across models. Since our estimations are not constrained to identical index aggregation, a large degree of correspondence between the individual index values across all models would underline the robustness of our results. Table 13 shows that the estimated indices are highly correlated across models, indicating that all four estimations lead to fairly similar conclusions regarding the relative importance of different individual, household and societal characteristics in forming the indices. Particularly, the correlation of the gender-specific indices is always above .6 and most of the time above .75 .

Table 13 about here

\section{Conclusion}

Decision processes among couples depend on the balance of power between the partners which is one of the factors determining the individual welfare of household members as well as household outcomes. A better understanding of its 
driving forces is therefore an essential prerequisite for the advancement of successful policies aimed at intra-household equality and gender empowerment.

Based on the Mexican Health and Aging Study, we exploit a unique measure of decision power within the household to analyze the impact of various individual, household and social characteristics on its distribution. On average, this measure of power points to somewhat more say of the male partner in the couple.

We analyze the determinants of self-assessed decision power within a flexible semiparametric modeling framework, featuring two indices that contain numerous characteristics of each partner. Our findings point to fairly complex relationships between both partners' demographic, socioeconomic and health characteristics on the one hand and decision power on the other. Especially gender-asymmetries and non-monotonicities appear to be important features of the relationships the individual characteristics of each partner on the one hand and decision power on the other.

We identify education and employment status as key individual-level characteristics affecting the balance of power. Higher educational attainment and active labor market participation affect both partners' decision power positively. We document some important asymmetries in the effect of male and female education on decision power. While a higher education level increases the male partner's decision power only moderately, the increase in the female partner's decision power is large if she features relatively high educational attainment. More generally, couples where both partners have relatively high levels of bargaining power also tend to feature a more equal distribution of say within the household. Moreover, we are also able to document some evidence for positive effects of good health on decision power, although this finding is somewhat less clear-cut. Particularly, poor health seems to lead to a loss of power of the male partner, while we do not find any corresponding effects for the female counterpart.

Finally, rural couples generally feature a less equal distribution of power than otherwise similar couples in urban areas, pointing to important effects of the social environment in the determination of say within the household.

\section{References}

Alessie, R., T. F. Crossley, and V. Hildebrand (2006). Estimating a collective household model with survey data on financial satisfaction. IFS Working Paper 06/19.

Andreoni, J., E. Brown, and I. Rischall (2003). Charitable giving by married couples: Who decides and why does it matter? The Journal of Human Resources 38, 111-133.

Apps, P. F. and R. Rees (1988). Taxation and the household. Journal of Public Economics 35, 355-369. 
Attanasio, O. and V. Lechene (2002). Tests of income pooling in household decisions. Review of Economic Dynamics 5(4), 720-748.

Beegle, K., E. Frankenberg, and D. Thomas (2001). Bargaining power within couples and use of prenatal and delivery care in Indonesia. Studies in Family Planning 32(2), 130-46.

Blundell, R., P.-A. Chiappori, T. Magnac, and C. Meghir (2005). Collective labor supply: Heterogeneity and nonparticipation. IZA Discussion Paper 1785.

Blundell, R., P.-A. Chiappori, and C. Meghir (2002). Collective labor supply with children. IFS Working Paper 02/08.

Browning, M. (1995). Saving and the intra-household distribution of income: An empirical investigation. Ricerche Economiche 49(3), 277-292.

Browning, M., F. Bourguignon, P.-A. Chiappori, and V. Lechene (1994). Income and outcomes: A structural model of intrahoushold allocation. Journal of Political Economy 102(6), 1067-96.

Browning, M., P.-A. Chiappori, and V. Lechene (2006). Distributional effects in household models: Separate spheres and income pooling. University of Oxford, Department of Economics Discussion Paper 293.

Browning, M., P.-A. Chiappori, and Y. Weiss (2007). Family Economics. Cambridge: Cambridge University Press.

Chiappori, P.-A. (1988). Nash-bargained household decisions. International Economic Review 32, 791-796.

Chiappori, P.-A. and I. Ekeland (2006). The micro economics of group behaviour: General characterization. Journal of Economic Theory 130, 1-26.

Donni, O. (2007). Collective female labour supply: Theory and application. Economic Journal 117(516), 94-119.

Duflo, E. (2000). Child health and household resources in south africa: Evidence from the old age pension program. American Economic Review 90(2), 393-398.

Duflo, E. (2003). Grandmothers and granddaughters: Old age pension and intra-household allocation in south africa. World Bank Economic Review 17(1), 1-25.

Ermisch, J. and C. Pronzato (2006). Intra-household allocation of resources: Inferences from non-resident fathers' child support payments. IZA Discussion Paper 2498.

Fortin, N. M. and G. Lacroix (1997). A test of unitary and collective models of household labor supply. Economic Journal 107(443), 933-955. 
Friedberg, L. and A. Webb (2006). Determinants and consequences of bargaining power in households. Center for Retirement Research at Boston College Working Paper 13.

Hoddinott, J. and L. Haddad (1995). Does female income share influence household expenditures? evidence from Cote d'Ivoire. Oxford Bulletin of Economics and Statistics 57(1), 77-96.

Ichimura, H. and L.-F. Lee (1991). Semiparametric estimation of multiple index models: Single equation estimation. In W. A. Barnett, J. L. Powell, and G. Tauchen (Eds.), Nonparametric and Semiparametric Methods in Econometrics and Statistics, International Symposia in Economic Theory and Econometrics. Cambridge, Mass.: Cambridge University Press.

INEGI (2003). Mexican Health and Aging Study (MHAS 2003) - Questionnaire Application Manual 2003. INEGI. National Institute of Statistics, Geography, and Informatics.

Klein, R. and F. Vella (2006). A semiparametric model for binary response and continuous outcomes under index heterogeneity. IZA Discussion Paper 2383.

Klein, R. W. and R. P. Sherman (2002). Shift restrictions and semiparametric estimation in ordered response models. Econometrica 70(2), 663-691.

Klein, R. W. and R. H. Spady (1993). An efficient semiparametric estimator for binary response models. Econometrica 61(2), 387-421.

Kooreman, P. (2000). The labeling effect of a child benefit system. American Economic Review $90(3), 571-83$.

Lee, Y.-S. and L. J. Waite (2005). Husbands' and wives' time spent on housework: A comparison of measures. Journal of Marriage and the Family 67, $328-336$.

Lundberg, S. and R. Pollak (1993). Separate spheres bargaining and the marriage market. Journal of Political Economy 101 (6), 988-1010.

Lundberg, S., R. Pollak, and T. Wales (1997). Do husbands and wives pool resources: Evidence from UK child benefit. Journal of Human Resources 32(3), 463-480.

Lundberg, S., R. Startz, and S. Stillman (2003). The retirement-consumption puzzle: A marital bargaining approach. Journal of Public Economics 87(56), 1199-1218.

Manser, M. and M. Brown (1980). Marriage and household decision-making: A bargaining analysis. International Economic Review 21, 31-44.

McElroy, M. and M. Horney (1981). Nash-bargained decisions: Toward a generalization of the theory of demand. International Economic Review 22(2), 333-349. 
Pezzin, L. E. and B. Steinberg Schone (1999). Intergenerational household formation, female labor supply and informal caregiving. Journal of Human Resources 34(3), 475-503.

Phipps, S. and P. Burton (1998). What's mine is yours? the influence of male and female incomes on patterns of household expenditure. Economica 65, 599-613.

Schuler, S. R. and S. M. Hashemi (1994). Credit programs, women's empowerment, and contraceptive use in rural bangladesh. Studies in Familiy Planning $25(2), 65-76$.

Schultz, P. T. (1990). Testing the neoclassical model of family labor supply and fertility. Journal of Human Resources 25 (4), 599-634.

Thomas, D. (1990). Intra-household resource allocation: An inferential approach. Journal of Human Resources 25 (4), 635-664.

Ward-Batts, J. (2003). Out of the wallet and into the purse: Using micro data to test income pooling. Technical Report 10, Claremont Colleges Working Paper.

\section{Appendix A1: Figures}

Figure 1: Averaged assessments: bivariate densities and probabilities conditional on male and female indices

(a)

Bivariate density estimates

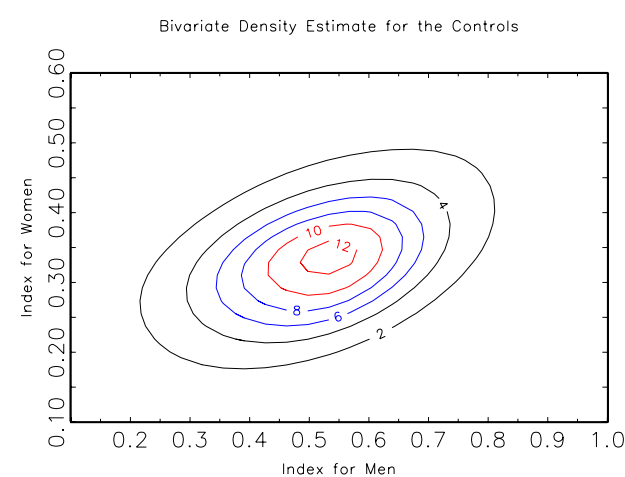

(b)

Expected decision weight

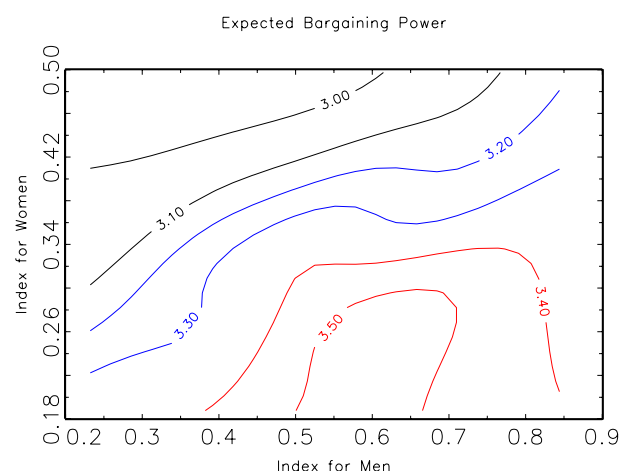

Note: The x-axis depicts the index of the man, the y-axis the index of the woman 
Figure 2: Agreements: bivariate densities and probabilities conditional on male and female indices

(a)

Bivariate density estimates

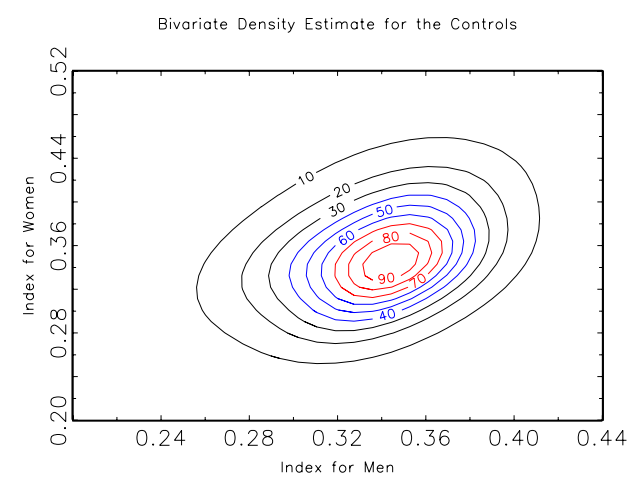

(c)

Probability for more say woman

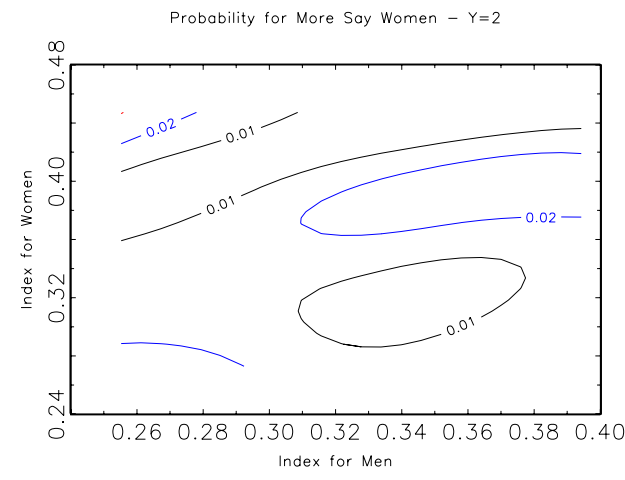

(e)

Probability for more say man

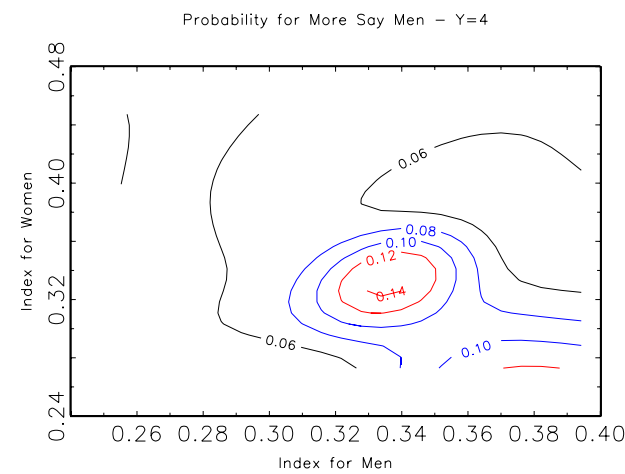

(b)

Probability for much more say woman

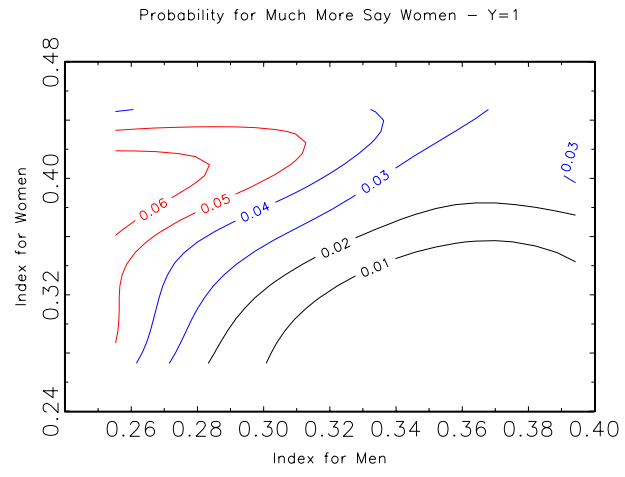

(d)

Probability for equal say

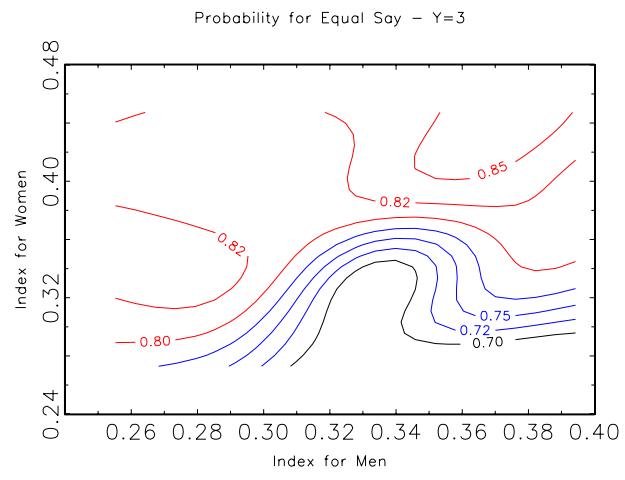

(f)

Probability for much more say man

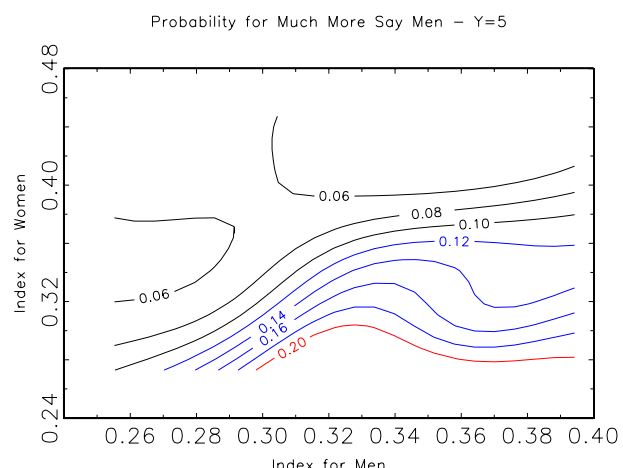

Note: The $\mathrm{x}$-axis depicts the index of the man, the $\mathrm{y}$-axis the index of the woman 
Figure 3: Male Assessments: bivariate densities and probabilities conditional on male and female indices

(a)

Bivariate density estimates

Bivariate Density Estimate for the Controls

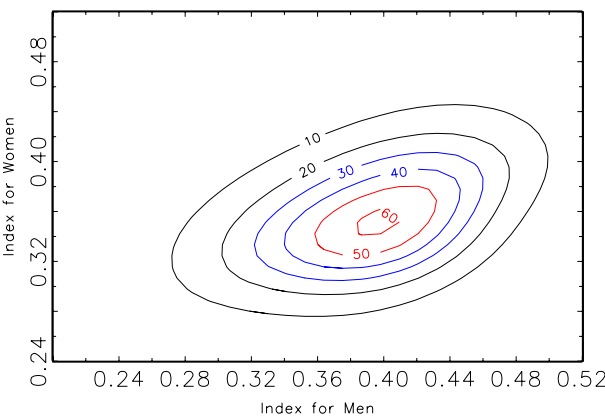

(c)

Probability for more say woman

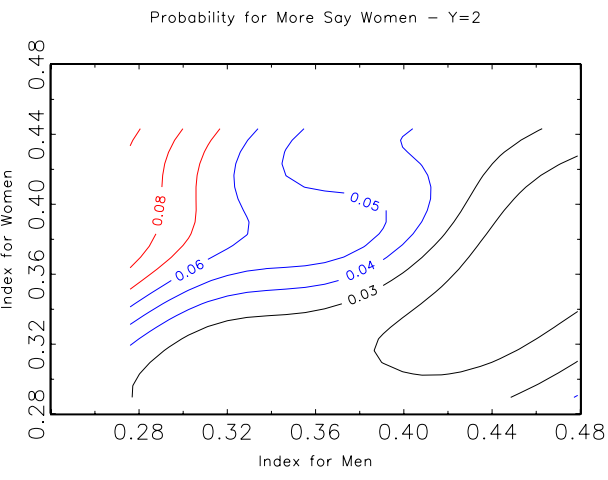

(e)

Probability for more say man

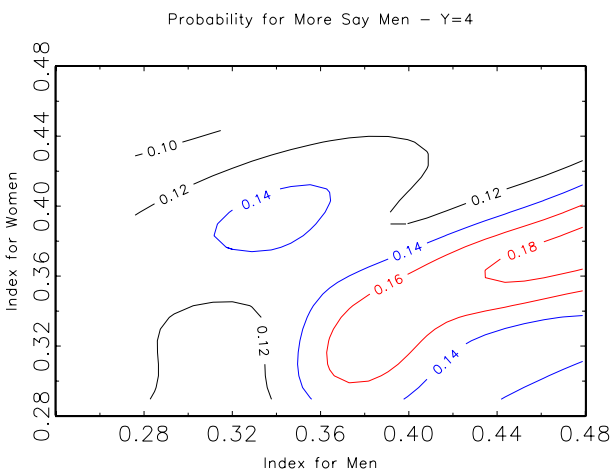

(b)

Probability for much more say woman

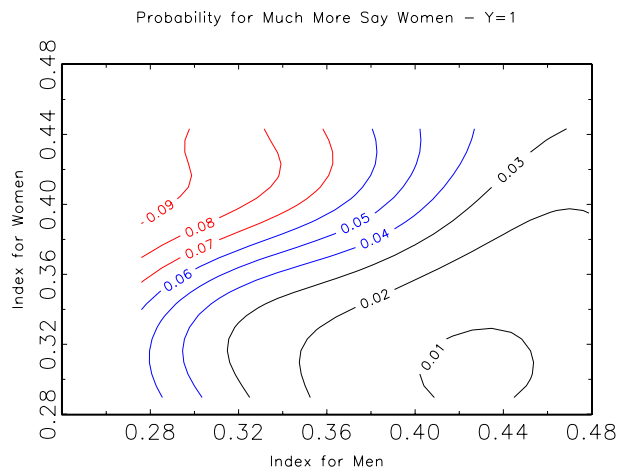

(d)

Probability for equal say

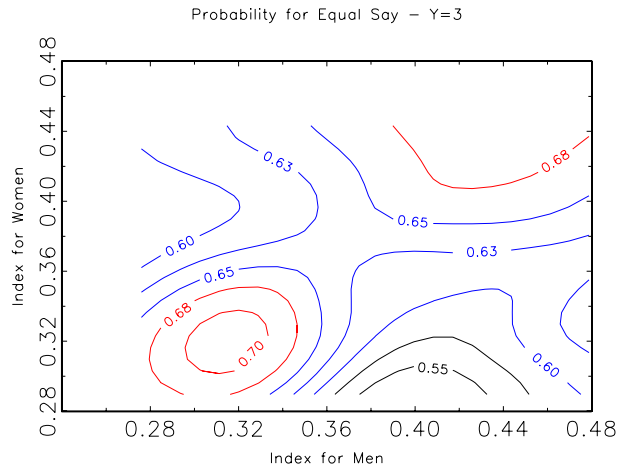

(f)

Probability for much more say man

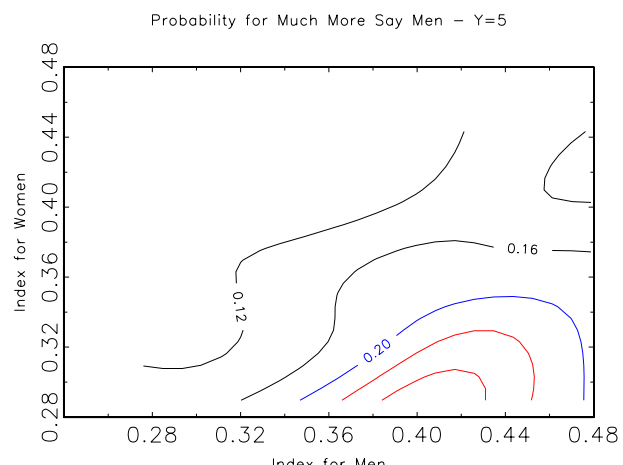

Note: The $\mathrm{x}$-axis depicts the index of the man, the y-axis the index of the woman 
Figure 4: Female Assessments: bivariate densities and probabilities conditional on male and female indices

(a)

Bivariate density estimates

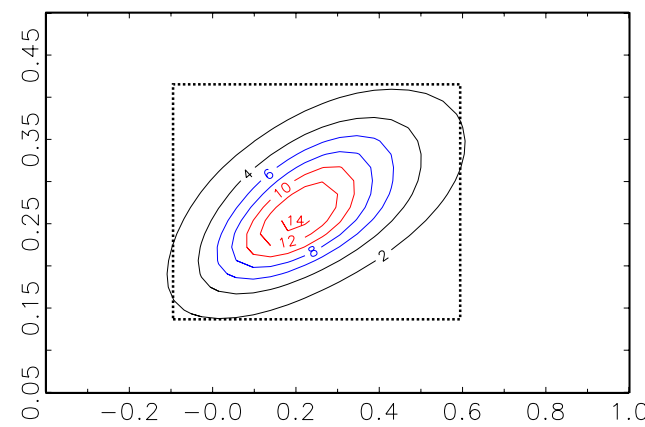

(c)

Probability for more say woman

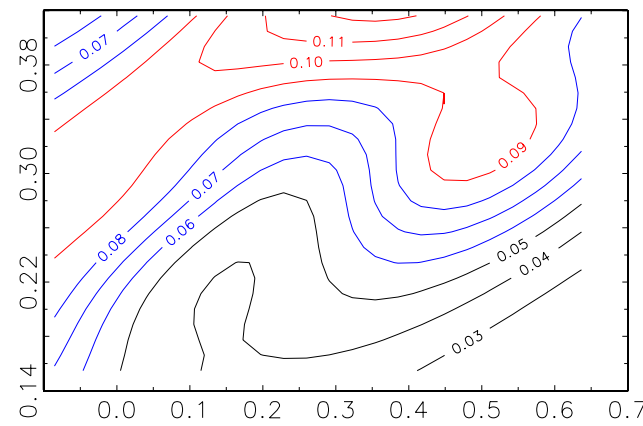

(e)

Probability for more say man

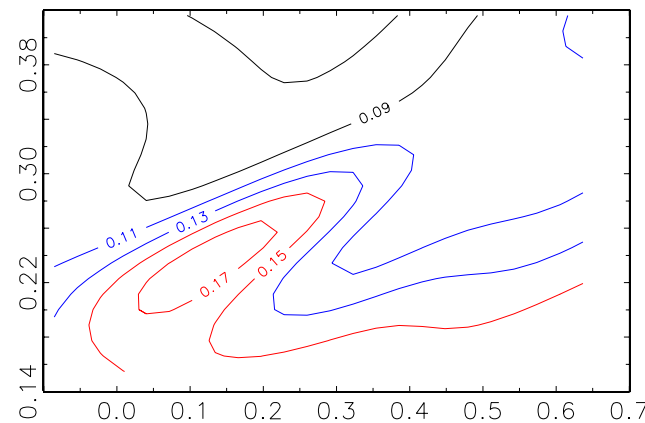

(b)

Probability for much more say woman

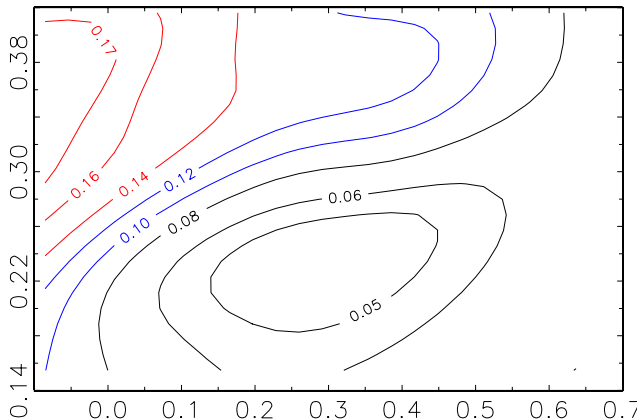

(d)

Probability for equal say

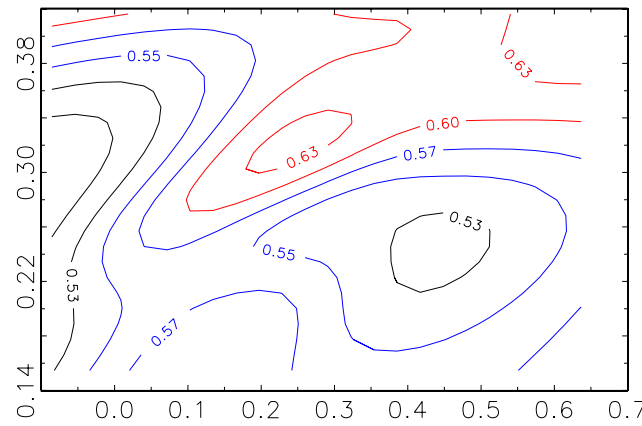

(f)

Probability for much more say man

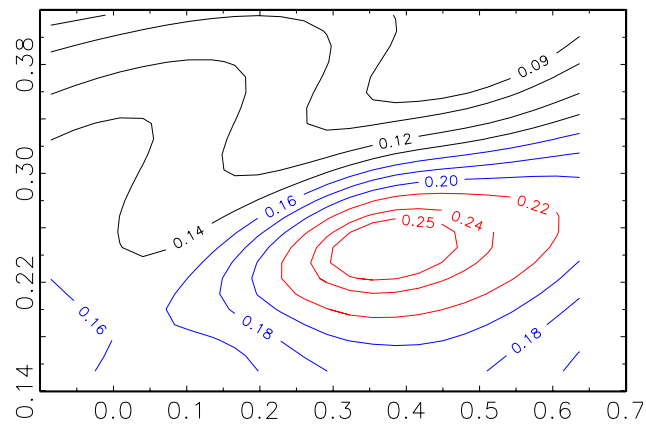

Note: The $\mathrm{x}$-axis depicts the index of the man, the $\mathrm{y}$-axis the index of the woman 


\section{Appendix A2: Tables}

Table 1: Partners' self-reported decision power

\begin{tabular}{|c|c|c|c|c|c|c|}
\hline & \multicolumn{3}{|c|}{ Men } & Women & \multicolumn{2}{|c|}{ Both } \\
\hline Decision Index & Freq. & Percent & Freq. & Percent & Freq. & Percent \\
\hline 1 & 118 & 3.34 & 302 & 8.52 & 420 & 5.93 \\
\hline 2 & 125 & 3.54 & 234 & 6.61 & 359 & 5.07 \\
\hline 3 & 2,227 & 63.00 & 2,031 & 57.32 & 4,258 & 60.16 \\
\hline 4 & 486 & 13.75 & 422 & 11.91 & 908 & 12.83 \\
\hline 5 & 579 & 16.38 & 554 & 15.64 & 1,133 & 16.01 \\
\hline Total & 3,535 & 100.00 & 3,543 & 100.00 & 7,078 & 100.00 \\
\hline
\end{tabular}

$1=$ she has much more say, $2=$ she has somewhat more say, $3=$ Equal say, $4=$ he has somewhat more say, $5=$ he has much more say

Table 2: Frequency of agreement in decision power reports

\begin{tabular}{ll|ccc}
\hline Degree of agreement & & Frequency & Percent & Cum. \\
\hline Perfect agreement & $(0)$ & 1,984 & 57.32 & 57.32 \\
Minor disagreement & $(1)$ & 748 & 21.61 & 78.93 \\
Medium disagreement & $(2)$ & 609 & 17.60 & 96.53 \\
Strong disagreement & $(3,4)$ & 120 & 3.47 & 100.00 \\
\hline Total & & 3,461 & 100.00 & 100.00 \\
\hline
\end{tabular}

Table 3: Descriptive statistics

\begin{tabular}{|c|c|c|c|c|c|c|c|c|}
\hline & \multicolumn{4}{|c|}{ Male Assessment Sample } & \multicolumn{4}{|c|}{ Female Assessment Sample } \\
\hline \multirow[t]{2}{*}{ Variable } & Mean & Std. & Mean & Std. & Mean & Std. & Mean & Std. \\
\hline & Men & & Women & & Men & & Women & \\
\hline Working & 0.690 & 0.463 & 0.240 & 0.427 & 0.690 & 0.463 & 0.244 & 0.429 \\
\hline Any mobility limit. & 0.498 & 0.500 & 0.618 & 0.486 & 0.498 & 0.500 & 0.619 & 0.486 \\
\hline Any ADL & 0.060 & 0.238 & 0.059 & 0.236 & 0.060 & 0.237 & 0.060 & 0.237 \\
\hline Any IADL & 0.047 & 0.211 & 0.064 & 0.244 & 0.046 & 0.210 & 0.064 & 0.245 \\
\hline Age & 63.380 & 8.869 & 58.255 & 9.568 & 63.320 & 8.833 & 58.216 & 9.558 \\
\hline Years of educ. & 4.985 & 4.705 & 4.385 & 3.948 & 5.002 & 4.719 & 4.417 & 3.975 \\
\hline \multirow{2}{*}{$\begin{array}{l}\text { Indiv. income } \\
\text { (in 10,000 MXN) }\end{array}$} & 0.441 & 0.661 & 0.246 & 0.524 & 0.441 & 0.659 & 0.246 & 0.521 \\
\hline & \multicolumn{4}{|c|}{ Household } & \multicolumn{4}{|c|}{ Household } \\
\hline Net worth (in 1,000$)$ & 0.447 & \multicolumn{3}{|l|}{0.524} & 0.446 & 0.522 & & \\
\hline Medium city size & 0.250 & \multicolumn{3}{|l|}{0.433} & 0.252 & 0.434 & & \\
\hline Rural area & 0.186 & \multicolumn{3}{|l|}{0.389} & 0.184 & 0.388 & & \\
\hline Observations & \multicolumn{4}{|l|}{3,535} & \multicolumn{4}{|l|}{3.543} \\
\hline
\end{tabular}


Table 4: Counterfactuals used to calculate partial effects

\begin{tabular}{l|l|l|l}
\hline Variable & Low to high & Men & Women \\
\hline Age & 1st to 4th quartile & 56 to 69 & 52 to 64 \\
Individual Income & 1st to 4th quartile & 1000 to $5800 \mathrm{MXN}$ & 0 to $2300 \mathrm{MXN}$ \\
Education & 1st to 4th quartile & 1 to 6 & 1 to 6 \\
Work & not working to working & 0 to 1 & 0 to 1 \\
Health limit. & none to ADL, IADL, & $0,0,0$ to $1,1,1$ & $0,0,0$ to $1,1,1$ \\
& mobility limit. & & \\
\hline Household Wealth & 1st to 4th quartile & 111,000 to 562,804 MXN \\
City size & urban to rural area & $>100,000$ to $<2,500$ inhab. \\
\hline
\end{tabular}

Table 5: Averaged assessments: Parameter Estimates for the Indices

\begin{tabular}{l|ccc|cccc}
\hline & \multicolumn{3}{|c}{ Men's } & characteristics & \multicolumn{3}{c}{ Women's characteristics } \\
\hline Variable & Par. & SE & p-Value & Par. & SE & p-Value \\
& Estim. & & & Estim. & & \\
\hline Age $/ 10^{2}$ & 1.0000 & & & - & 1.0000 & & \\
$\left.\left(\text { Age } / 10^{2}\right)^{2}\right)$ & -0.6595 & 0.1177 & 0.0000 & -0.7055 & 0.0777 & 0.0000 \\
Household Wealth $/ 10^{6}$ & -0.4299 & 0.4874 & 0.3778 & -0.2526 & 0.1486 & 0.0892 \\
$\left(\text { Household Wealth } / 10^{6}\right)^{2}$ & 0.1073 & 0.1235 & 0.3851 & 0.0679 & 0.0391 & 0.0827 \\
Income $/ 10^{4}$ & 0.2634 & 0.3268 & 0.4203 & 0.0781 & 0.0597 & 0.1912 \\
(Income $\left./ 10^{4}\right)^{2}$ & -0.0378 & 0.0535 & 0.4792 & -0.0068 & 0.0103 & 0.5106 \\
Years of education & 0.0234 & 0.0236 & 0.3218 & 0.0141 & 0.0057 & 0.0140 \\
Working & 0.1284 & 0.1290 & 0.3194 & 0.0759 & 0.0310 & 0.0143 \\
Any mobility limitation & -0.0162 & 0.0199 & 0.4149 & 0.0165 & 0.0192 & 0.3922 \\
Any ADL & -0.1055 & 0.1711 & 0.5373 & -0.0224 & 0.0211 & 0.2879 \\
Any IADL & -0.0107 & 0.0415 & 0.7959 & -0.0364 & 0.0231 & 0.1159 \\
Rural area & 0.0680 & 0.0715 & 0.3414 & -0.0214 & 0.0158 & 0.1763 \\
Medium city size & 0.0342 & 0.0516 & 0.5069 & -0.0869 & 0.0377 & 0.0213 \\
\hline
\end{tabular}

Table 6: Averaged Assessments: Average Partial Effects - Absolute Changes in Probabilities

\begin{tabular}{l|ccc}
\hline & Men & Women & Both \\
\hline Age (Low to High) & 0.0126 & -0.0366 & -0.0236 \\
Individual Income (Low to High) & 0.0515 & -0.0296 & 0.0212 \\
Education (Low to High) & 0.0896 & -0.1783 & -0.0757 \\
Work (no Work to Work) & 0.0797 & -0.1380 & -0.0612 \\
Health (Good to Bad) & -0.0850 & 0.0631 & -0.0170 \\
Household Wealth (Low to High) & - & - & 0.0527 \\
City Size (Large to Small) & - & - & 0.1566 \\
\hline
\end{tabular}


Table 7: Agreements: Parameter Estimates for the Indices

\begin{tabular}{|c|c|c|c|c|c|c|}
\hline & \multicolumn{3}{|c|}{ Men's characteristics } & \multicolumn{3}{|c|}{ Women's characteristics } \\
\hline Variable & $\begin{array}{c}\text { Par. } \\
\text { Estim. }\end{array}$ & $\mathrm{SE}$ & $\mathrm{p}$-Value & $\begin{array}{c}\text { Par. } \\
\text { Estim. }\end{array}$ & $\mathrm{SE}$ & p-Value \\
\hline Age $/ 10^{2}$ & 1 & 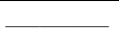 & - & 1.0000 & 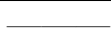 & $\ldots$ \\
\hline$\left(\text { Age } / 10^{2}\right)^{2}$ & -0.7696 & 0.0292 & 0.0000 & -0.6900 & 0.0700 & 0.0000 \\
\hline Household Wealth $/ 10^{6}$ & -0.0523 & 0.0276 & 0.0584 & -0.0488 & 0.0552 & 0.3773 \\
\hline$\left(\text { Household Wealth } / 10^{6}\right)^{2}$ & -0.0018 & 0.0169 & 0.9138 & -0.0048 & 0.0201 & 0.8101 \\
\hline Income $/ 10^{4}$ & 0.0427 & 0.0274 & 0.1187 & 0.0144 & 0.0278 & 0.6056 \\
\hline$\left(\text { Income } / 10^{4}\right)^{2}$ & -0.0040 & 0.0082 & 0.6304 & -0.0020 & 0.0133 & 0.8776 \\
\hline Years of education & 0.0028 & 0.0016 & 0.0778 & 0.0083 & 0.0043 & 0.0513 \\
\hline Working & 0.0293 & 0.0138 & 0.0335 & 0.0641 & 0.0245 & 0.0090 \\
\hline Any mobility limitation & -0.0212 & 0.0188 & 0.2602 & -0.0176 & 0.0121 & 0.1463 \\
\hline Any ADL & 0.0366 & 0.0159 & 0.0210 & -0.0103 & 0.0389 & 0.7911 \\
\hline Any IADL & -0.0775 & 0.0201 & 0.0001 & -0.0191 & 0.0224 & 0.3943 \\
\hline Rural area & 0.0139 & 0.0077 & 0.0720 & -0.0020 & 0.0098 & 0.8423 \\
\hline Medium city size & -0.0130 & 0.0200 & 0.5173 & -0.0427 & 0.0178 & 0.0164 \\
\hline
\end{tabular}


Table 8: Agreements: Estimated Average Partial Effects - Absolute Changes in Probabilities

\begin{tabular}{|c|c|c|c|}
\hline & Men & Women & Both \\
\hline \multicolumn{4}{|c|}{ Age (Low to High) } \\
\hline$E[\Delta P(Y=1)]$ & -0.0011 & 0.0045 & 0.0035 \\
\hline$E[\Delta P(Y=2)]$ & 0.0000 & 0.0005 & 0.0004 \\
\hline$E[\Delta P(Y=3)]$ & -0.0010 & 0.0218 & 0.0210 \\
\hline$E[\Delta P(Y=4)]$ & 0.0000 & -0.0028 & -0.0027 \\
\hline$E[\Delta P(Y=5)]$ & 0.0021 & -0.0239 & -0.0221 \\
\hline \multicolumn{4}{|c|}{ Individual Income (Low to High) } \\
\hline$E[\Delta P(Y=1)]$ & -0.0041 & 0.0006 & -0.0034 \\
\hline$E[\Delta P(Y=2)]$ & -0.0001 & 0.0001 & 0.0000 \\
\hline$E[\Delta P(Y=3)]$ & -0.0008 & 0.0030 & 0.0024 \\
\hline$E[\Delta P(Y=4)]$ & -0.0008 & -0.0004 & -0.0014 \\
\hline$E[\Delta P(Y=5)]$ & 0.0057 & -0.0032 & 0.0025 \\
\hline \multicolumn{4}{|c|}{ Education (Low to High) } \\
\hline$E[\Delta P(Y=1)]$ & -0.0037 & 0.0092 & 0.0056 \\
\hline$E[\Delta P(Y=2)]$ & 0.0000 & 0.0019 & 0.0020 \\
\hline$E[\Delta P(Y=3)]$ & -0.0008 & 0.0423 & 0.0406 \\
\hline$E[\Delta P(Y=4)]$ & -0.0005 & -0.0095 & -0.0097 \\
\hline$E[\Delta P(Y=5)]$ & 0.0050 & -0.0439 & -0.0385 \\
\hline \multicolumn{4}{|c|}{ Work (no Work to Work) } \\
\hline$E[\Delta P(Y=1)]$ & -0.0085 & 0.0143 & 0.0063 \\
\hline$E[\Delta P(Y=2)]$ & -0.0006 & -0.0004 & -0.0006 \\
\hline$E[\Delta P(Y=3)]$ & -0.0132 & 0.0557 & 0.0478 \\
\hline$E[\Delta P(Y=4)]$ & 0.0041 & -0.0127 & -0.0107 \\
\hline$E[\Delta P(Y=5)]$ & 0.0182 & -0.0569 & -0.0427 \\
\hline \multicolumn{4}{|c|}{ Health (Good to Bad) } \\
\hline$E[\Delta P(Y=1)]$ & 0.0242 & -0.0087 & 0.0144 \\
\hline$E[\Delta P(Y=2)]$ & 0.0004 & -0.0001 & 0.0018 \\
\hline$E[\Delta P(Y=3)]$ & 0.0355 & -0.0466 & 0.0003 \\
\hline$E[\Delta P(Y=4)]$ & -0.0173 & 0.0065 & -0.0141 \\
\hline$E[\Delta P(Y=5)]$ & -0.0427 & 0.0489 & -0.0024 \\
\hline \multicolumn{4}{|c|}{ Household Wealth (Low to High) } \\
\hline$E[\Delta P(Y=1)]$ & & & 0.0008 \\
\hline$E[\Delta P(Y=2)]$ & & & 0.0000 \\
\hline$E[\Delta P(Y=3)]$ & 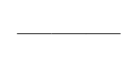 & & -0.0163 \\
\hline$E[\Delta P(Y=4)]$ & & & 0.0020 \\
\hline$E[\Delta P(Y=5)]$ & & & 0.0134 \\
\hline \multicolumn{4}{|c|}{ City Size (Large to Small) } \\
\hline$E[\Delta P(Y=1)]$ & & & -0.0045 \\
\hline$E[\Delta P(Y=2)]$ & & & -0.0001 \\
\hline$E[\Delta P(Y=3)]$ & & & -0.0370 \\
\hline$E[\Delta P(Y=4)]$ & $\overline{20}$ & & 0.0015 \\
\hline$E[\Delta P(Y=5)]$ & 30 & & 0.0401 \\
\hline
\end{tabular}


Table 9: Male Assessments: Parameter Estimates for the Indices

\begin{tabular}{lccc|ccc}
\hline & \multicolumn{3}{c}{ Men's } & characteristics & \multicolumn{3}{c}{ Women's characteristics } \\
\hline & Par. Est. & SE & p-Value & Par. Est. & SE & p-Value \\
\hline Age $/ 10^{2}$ & 1 & - & - & 1.0000 & - & - \\
$\left(\text { Age } / 10^{2}\right)^{2}$ & -0.7762 & 0.0369 & 0.0000 & -0.7905 & 0.0408 & 0.0000 \\
Household Wealth $/ 10^{6}$ & -0.0882 & 0.0288 & 0.0022 & -0.0825 & 0.0190 & 0.0000 \\
(Household Wealth $\left./ 10^{6}\right)^{2}$ & 0.0215 & 0.0088 & 0.0146 & 0.0212 & 0.0052 & 0.0001 \\
Income $/ 10^{4}$ & 0.0609 & 0.0208 & 0.0034 & 0.0381 & 0.0097 & 0.0001 \\
Income $\left./ 10^{4}\right)^{2}$ & -0.0094 & 0.0038 & 0.0131 & -0.0041 & 0.0020 & 0.0400 \\
Years of education & 0.0055 & 0.0014 & 0.0001 & 0.0083 & 0.0020 & 0.0000 \\
Working & 0.0577 & 0.0190 & 0.0024 & 0.0433 & 0.0107 & 0.0001 \\
Any mobility limitation & -0.0184 & 0.0107 & 0.0863 & 0.0243 & 0.0071 & 0.0006 \\
Any ADL & -0.0305 & 0.0175 & 0.0807 & -0.0127 & 0.0148 & 0.3908 \\
Any IADL & -0.0403 & 0.0158 & 0.0109 & -0.0089 & 0.0119 & 0.4528 \\
Rural area & 0.0712 & 0.0209 & 0.0007 & 0.0471 & 0.0137 & 0.0006 \\
Medium city size & 0.0420 & 0.0145 & 0.0039 & -0.0014 & 0.0086 & 0.8683 \\
\hline \# Obs. & 3,535 & & & & & \\
\hline
\end{tabular}


Table 10: Male Assessments: Estimated Average Partial Effects - Absolute Changes in Probabilities

\begin{tabular}{|c|c|c|c|}
\hline & Men & Women & Both \\
\hline \multicolumn{4}{|c|}{ Age (Low to High) } \\
\hline$E[\Delta P(Y=1)]$ & -0.0010 & 0.0027 & 0.0017 \\
\hline$E[\Delta P(Y=2)]$ & -0.0008 & 0.0022 & 0.0013 \\
\hline$E[\Delta P(Y=3)]$ & -0.0008 & 0.0045 & 0.0040 \\
\hline$E[\Delta P(Y=4)]$ & 0.0007 & -0.0018 & -0.0011 \\
\hline$E[\Delta P(Y=5)]$ & 0.0018 & -0.0076 & -0.0059 \\
\hline \multicolumn{4}{|c|}{ Individual Income (Low to High) } \\
\hline$E[\Delta P(Y=1)]$ & -0.0058 & 0.0022 & -0.0034 \\
\hline$E[\Delta P(Y=2)]$ & -0.0050 & 0.0016 & -0.0032 \\
\hline$E[\Delta P(Y=3)]$ & -0.0038 & 0.0042 & -0.0002 \\
\hline$E[\Delta P(Y=4)]$ & 0.0038 & -0.0012 & 0.0028 \\
\hline$E[\Delta P(Y=5)]$ & 0.0108 & -0.0069 & 0.0040 \\
\hline \multicolumn{4}{|c|}{ Education (Low to High) } \\
\hline$E[\Delta P(Y=1)]$ & -0.0077 & 0.0111 & 0.0040 \\
\hline$E[\Delta P(Y=2)]$ & -0.0065 & 0.0082 & 0.0029 \\
\hline$E[\Delta P(Y=3)]$ & -0.0037 & 0.0199 & 0.0125 \\
\hline$E[\Delta P(Y=4)]$ & 0.0048 & -0.0057 & 0.0001 \\
\hline$E[\Delta P(Y=5)]$ & 0.0130 & -0.0335 & -0.0195 \\
\hline \multicolumn{4}{|c|}{ Work (no Work to Work) } \\
\hline$E[\Delta P(Y=1)]$ & -0.0175 & 0.0138 & -0.0035 \\
\hline$E[\Delta P(Y=2)]$ & -0.0136 & 0.0112 & -0.0029 \\
\hline$E[\Delta P(Y=3)]$ & -0.0165 & 0.0165 & 0.0021 \\
\hline$E[\Delta P(Y=4)]$ & 0.0134 & -0.0125 & 0.0009 \\
\hline$E[\Delta P(Y=5)]$ & 0.0342 & -0.0289 & 0.0035 \\
\hline \multicolumn{4}{|c|}{ Health (Good to Bad) } \\
\hline$E[\Delta P(Y=1)]$ & 0.0314 & 0.0006 & 0.0308 \\
\hline$E[\Delta P(Y=2)]$ & 0.0254 & 0.0004 & 0.0234 \\
\hline$E[\Delta P(Y=3)]$ & 0.0024 & 0.0017 & 0.0153 \\
\hline$E[\Delta P(Y=4)]$ & -0.0159 & -0.0001 & -0.0174 \\
\hline$E[\Delta P(Y=5)]$ & -0.0433 & -0.0025 & -0.0521 \\
\hline \multicolumn{4}{|c|}{ Household Wealth (Low to High) } \\
\hline$E[\Delta P(Y=1)]$ & & & 0.0001 \\
\hline$E[\Delta P(Y=2)]$ & & & 0.0011 \\
\hline$E[\Delta P(Y=3)]$ & & & -0.0082 \\
\hline$E[\Delta P(Y=4)]$ & - & & -0.0007 \\
\hline$E[\Delta P(Y=5)]$ & 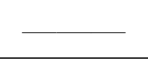 & - & 0.0077 \\
\hline \multicolumn{4}{|c|}{ City Size (Large to Small) } \\
\hline$E[\Delta P(Y=1)]$ & 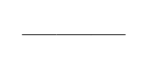 & 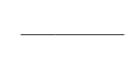 & -0.0108 \\
\hline$E[\Delta P(Y=2)]$ & & & -0.0091 \\
\hline$E[\Delta P(Y=3)]$ & . & & -0.0125 \\
\hline$E[\Delta P(Y=4)]$ & 32 & & 0.0068 \\
\hline$E[\Delta P(Y=5)]$ & 32 & & 0.0257 \\
\hline
\end{tabular}


Table 11: Female Assessments: Parameter Estimates for the Indices

\begin{tabular}{|c|c|c|c|c|c|c|}
\hline & \multicolumn{3}{|c|}{ Men's characteristics } & \multicolumn{3}{|c|}{ Women's characteristics } \\
\hline & Par. Est. & SE & p-Value & Par. Est. & $\mathrm{SE}$ & p-Value \\
\hline Age $/ 10^{2}$ & 1.0000 & 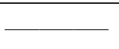 & $\longrightarrow$ & 1.0000 & $\bar{z}$ & 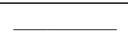 \\
\hline$\left(\text { Age } / 10^{2}\right)^{2}$ & -1.3240 & 0.9796 & 0.1765 & -0.8884 & 0.0369 & 0.0000 \\
\hline Household Wealth/10² & -0.2869 & 0.4897 & 0.5579 & -0.1533 & 0.0515 & 0.0029 \\
\hline (Household Wealth $\left./ 10^{2}\right)^{2}$ & 0.0537 & 0.0951 & 0.5726 & 0.0286 & 0.0142 & 0.0445 \\
\hline Income $/ 10^{4}$ & 0.1351 & 0.2319 & 0.5603 & 0.0451 & 0.0224 & 0.0443 \\
\hline$\left(\text { Income } / 10^{4}\right)^{2}$ & -0.0054 & 0.0177 & 0.7619 & -0.0052 & 0.0062 & 0.3999 \\
\hline Years of education & 0.0349 & 0.0598 & 0.5590 & 0.0139 & 0.0044 & 0.0016 \\
\hline Working & -0.0369 & 0.0680 & 0.5872 & 0.0601 & 0.0204 & 0.0032 \\
\hline Any mobility limitation & 0.1077 & 0.1868 & 0.5643 & -0.0180 & 0.0085 & 0.0351 \\
\hline Any ADL & -0.1139 & 0.1991 & 0.5674 & 0.0129 & 0.0131 & 0.3258 \\
\hline Any IADL & -0.1799 & 0.3140 & 0.5666 & 0.0119 & 0.0121 & 0.3263 \\
\hline Rural area & 0.0686 & 0.1220 & 0.5742 & -0.0167 & 0.0107 & 0.1175 \\
\hline Medium city size & 0.0268 & 0.0593 & 0.6509 & -0.0585 & 0.0213 & 0.0060 \\
\hline \# Obs. & 3,543 & & & & & \\
\hline
\end{tabular}


Table 12: Female Assessments: Estimated Average Partial Effects - Absolute Changes in Probabilities

\begin{tabular}{|c|c|c|c|}
\hline & Men & Women & Both \\
\hline \multicolumn{4}{|c|}{ Age (Low to High) } \\
\hline$E[\Delta P(Y=1)]$ & 0.0109 & -0.0010 & 0.0104 \\
\hline$E[\Delta P(Y=2)]$ & 0.0021 & -0.0006 & 0.0015 \\
\hline$E[\Delta P(Y=3)]$ & -0.0006 & -0.0007 & -0.0013 \\
\hline$E[\Delta P(Y=4)]$ & -0.0013 & 0.0008 & -0.0006 \\
\hline$E[\Delta P(Y=5)]$ & -0.0112 & 0.0015 & -0.0099 \\
\hline \multicolumn{4}{|c|}{ Individual Income (Low to High) } \\
\hline$E[\Delta P(Y=1)]$ & -0.0069 & 0.0035 & -0.0032 \\
\hline$E[\Delta P(Y=2)]$ & -0.0012 & 0.0021 & 0.0008 \\
\hline$E[\Delta P(Y=3)]$ & 0.0010 & 0.0024 & 0.0032 \\
\hline$E[\Delta P(Y=4)]$ & 0.0010 & -0.0026 & -0.0017 \\
\hline$E[\Delta P(Y=5)]$ & 0.0061 & -0.0054 & 0.0008 \\
\hline \multicolumn{4}{|c|}{ Education (Low to High) } \\
\hline$E[\Delta P(Y=1)]$ & -0.0253 & 0.0330 & 0.0103 \\
\hline$E[\Delta P(Y=2)]$ & -0.0008 & 0.0165 & 0.0142 \\
\hline$E[\Delta P(Y=3)]$ & 0.0023 & 0.0219 & 0.0240 \\
\hline$E[\Delta P(Y=4)]$ & 0.0002 & -0.0249 & -0.0245 \\
\hline$E[\Delta P(Y=5)]$ & 0.0236 & -0.0465 & -0.0241 \\
\hline \multicolumn{4}{|c|}{ Work (no Work to Work) } \\
\hline$E[\Delta P(Y=1)]$ & 0.0048 & 0.0260 & 0.0307 \\
\hline$E[\Delta P(Y=2)]$ & 0.0010 & 0.0138 & 0.0148 \\
\hline$E[\Delta P(Y=3)]$ & -0.0005 & 0.0162 & 0.0153 \\
\hline$E[\Delta P(Y=4)]$ & -0.0008 & -0.0207 & -0.0214 \\
\hline$E[\Delta P(Y=5)]$ & -0.0045 & -0.0353 & -0.0394 \\
\hline \multicolumn{4}{|c|}{ Health (Good to Bad) } \\
\hline$E[\Delta P(Y=1)]$ & 0.0359 & -0.0003 & 0.0355 \\
\hline$E[\Delta P(Y=2)]$ & 0.0105 & -0.0002 & 0.0095 \\
\hline$E[\Delta P(Y=3)]$ & -0.0289 & -0.0002 & -0.0312 \\
\hline$E[\Delta P(Y=4)]$ & -0.0119 & 0.0003 & -0.0105 \\
\hline$E[\Delta P(Y=5)]$ & -0.0056 & 0.0005 & -0.0033 \\
\hline \multicolumn{4}{|c|}{ Household Wealth (Low to High) } \\
\hline$E[\Delta P(Y=1)]$ & - & 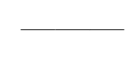 & -0.0053 \\
\hline$E[\Delta P(Y=2)]$ & 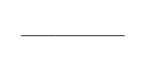 & 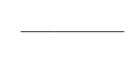 & -0.0084 \\
\hline$E[\Delta P(Y=3)]$ & 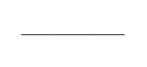 & & -0.0169 \\
\hline$E[\Delta P(Y=4)]$ & 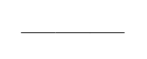 & & 0.0133 \\
\hline$E[\Delta P(Y=5)]$ & - & & 0.0174 \\
\hline \multicolumn{4}{|c|}{ City Size (Large to Small) } \\
\hline$E[\Delta P(Y=1)]$ & & & -0.0217 \\
\hline$E[\Delta P(Y=2)]$ & - & & -0.0117 \\
\hline$E[\Delta P(Y=3)]$ & 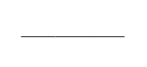 & & -0.0114 \\
\hline$E[\Delta P(Y=4)]$ & 34 & & 0.0136 \\
\hline$E[\Delta P(Y=5)]$ & 34 & & 0.0312 \\
\hline
\end{tabular}


Table 13: Correlation of the indices across estimations

\begin{tabular}{l|rrrr}
\hline \multicolumn{5}{c}{ Male Partner's Index } \\
\hline Pooled & Pooled & Agreements & Male Assessment & Female Assessment \\
Agreements & 1.00 & 0.78 & 0.85 & 0.81 \\
Male Assessment & & 1.00 & 0.79 & 0.63 \\
Female Assessment & & & 1.00 & 0.63 \\
& & & & 1.00 \\
\hline
\end{tabular}

Female Partner's Index

\begin{tabular}{l|rrrr}
\hline & Pooled & Agreements & Male Assessment & Female Assessment \\
\hline Pooled & 1.00 & 0.84 & 0.84 & 0.91 \\
Agreements & & 1.00 & 0.74 & 0.88 \\
Male Assessment & & & 1.00 & 0.77 \\
Female Assessment & & & & 1.00 \\
\hline
\end{tabular}




\section{Discussion Paper Series}

Mannheim Research Institute for the Economics of Aging Universität Mannheim

To order copies, please direct your request to the author of the title in question.

\begin{tabular}{|c|c|c|c|}
\hline Nr. & Autoren & Titel & Jahr \\
\hline 156-08 & $\begin{array}{l}\text { Florian Heiss, } \\
\text { Daniel McFadden, } \\
\text { Joachim Winter }\end{array}$ & $\begin{array}{l}\text { Mind the Gap! Consumer Perceptions and } \\
\text { Choices of Medicare Part D Prescription Drug } \\
\text { Plans }\end{array}$ & 08 \\
\hline $157-08$ & Wolfgang Kuhle & Demography and Equity Premium & 08 \\
\hline $158-08$ & \begin{tabular}{|l|} 
Axel Börsch-Supan, \\
Tabea Bucher-Koenen, \\
Anette Reil-Held, \\
Christina Wilke
\end{tabular} & $\begin{array}{l}\text { Zum künftigen Stellenwert der ersten Säule im } \\
\text { Gesamtsystem der Alterssicherung }\end{array}$ & 08 \\
\hline $159-08$ & $\begin{array}{l}\text { Tabea Bucher-Koenen, } \\
\text { Christina Benita Wilke }\end{array}$ & $\begin{array}{l}\text { Zur Anhebung der Altersgrenze: Eine Simulation } \\
\text { der langfristigen Auswirkungen auf die gesetz- } \\
\text { liche Rentenversicherung bei unterschiedlichem } \\
\text { Renteneintrittsverhalten }\end{array}$ & 08 \\
\hline $160-08$ & Mathias Sommer & $\begin{array}{l}\text { Imputation and Harmonisation of Income, } \\
\text { Consumption, Savings and Wealth Data from } \\
\text { the German Income and Expenditure Survey }\end{array}$ & 08 \\
\hline $161-08$ & Karsten Hank & Generationenbeziehungen im alternden Europa & 08 \\
\hline $162-08$ & $\begin{array}{l}\text { Axel Börsch-Supan, } \\
\text { Karsten Hank, } \\
\text { Hendrik Jürges, } \\
\text { Mathis Schröder } \\
\end{array}$ & $\begin{array}{l}\text { Longitudinal Data Collection in Continental } \\
\text { Europe: Experiences from the Survey of Health, } \\
\text { Ageing and Retirement in (SHARE) }\end{array}$ & 08 \\
\hline $163-08$ & Martin Salm & Job loss does not cause ill health & 08 \\
\hline 164-08 & $\begin{array}{l}\text { Martin Salm, Daniel } \\
\text { Schunk }\end{array}$ & $\begin{array}{l}\text { The role of childhood health for the inter- } \\
\text { generational transmission of human capital: } \\
\text { Evidence from administrative data }\end{array}$ & 08 \\
\hline $165-08$ & Christina Benita Wilke & $\begin{array}{l}\text { On the feasibility of notional defined contribution } \\
\text { systems: The German case }\end{array}$ & 08 \\
\hline $166-08$ & $\begin{array}{l}\text { Alexander Ludwig } \\
\text { Michael Reiter }\end{array}$ & $\begin{array}{l}\text { Sharing Demographic Risk - Who is Afraid of } \\
\text { the Baby Bust? }\end{array}$ & 08 \\
\hline $167-08$ & $\begin{array}{l}\text { Jürgen Maurer } \\
\text { André Meier }\end{array}$ & $\begin{array}{l}\text { Smooth it Like the "Joneses?" Estimating Peer- } \\
\text { Group Effects in Intertemporal Consumption } \\
\text { Choice }\end{array}$ & 08 \\
\hline $168-08$ & $\begin{array}{l}\text { Melanie Lührmann } \\
\text { Jürgen Maurer }\end{array}$ & $\begin{array}{l}\text { Who wears the trousers? A semiparametric } \\
\text { analysis of decision power in couples }\end{array}$ & 08 \\
\hline
\end{tabular}

